Cadernos de Arquitetura e Urbanismo, v.17, n.21, 20 sem. 2010 
1. Arquiteto urbanista pela PUC Minas, mestre em Arquitetura e Urbanismo pelo Núcleo de Pós-graduação em Arquitetura e Urbanismo da UFMG, sóciodiretor da P20 Arquitetura Urbanismo e Meio Ambiente Ltda. 


\title{
PROCESSOS REGIONAIS, INSTRUMENTOS URBANÍSTICOS MUNICIPAIS: UMA ABORDAGEM DA CHAMADA REDE URBANA DO ALTO PARAOPEBA, MINAS GERAIS
}

\author{
REGIONAL PROCESSES, CITY URBAN INSTRUMENTS: A DISCUSSION \\ ABOUTTHE URBAN NETWORK OF ALTO PARAOPEBA, MINAS GERAIS
}

Leandro de Aguiar e Souza ${ }^{1}$

\begin{abstract}
Resumo
O presente trabalho tem o objetivo de discutir, no âmbito da formação da rede urbana do Alto Paraopeba, os limites das estruturas de planejamento e gestão urbana vigentes. A região em tela, ao passar por significativas mudanças decorrentes da ampliação e implantação de empreendimentos vinculados à extração e ao beneficiamento de minérios, tem o desafio de buscar alternativas para o planejamento e a gestão urbana de abrangência regional. Tal desafio concentra-se principalmente na competência delegada aos municípios nas questões vinculadas à execução da política urbana. Em contextos que envolvem impactos de abrangência regional, as instâncias reguladoras municipais não têm se mostrado suficientes para suportar a dimensão de tais processos. Desse modo, busca-se analisar situações em que o conflito municipal/regional é identificado e as alternativas e possibilidades voltadas à busca do planejamento urbano regional.
\end{abstract}

Palavras-chave: Rede urbana; Planejamento urbano; Planejamento regional; Política urbana.

\begin{abstract}
This research was conducted with the main objective to debate, in the scope of the Alto Paraopeba urban network formation, the limits of the structures of urban planning and management regulations. The region in question, by pass through significant changes resulting from the implantation and increase of enterprises linked to the extraction and beneficiation of minerals, has the challenge to seek alternatives for planning and urban management at a regional level. Such challenge focuses primarily on the power delegated to municipalities on issues related to the urban policy. In contexts that involve impacts at a regional level, the municipal regulatory bodies have not proved sufficient to support the scale of such processes. In the manner we analyze situations of identified conflict at municipal / regional levels and where the alternatives and opportunities seek a regional urban planning.
\end{abstract}

Key words: Urban network; Urban planning; Regional planning; Urban policy. 


\section{Contextualização}

O território formado pelos municípios de Belo Vale, Congonhas, Conselheiro Lafaiete, Entre Rios de Minas, Jeceaba, Ouro Branco e São Brás do Suaçuí tem parte de sua área localizada no polígono do chamado Quadrilátero Ferrífero, base para o estabelecimento de um ciclo que se inicia na extração de minérios e estabelece uma cadeia produtiva que dá à área um significativo potencial para o estabelecimento de processos urbanos de grande porte.

Do ponto de vista histórico o processo de urbanização da área remete ao século XVIII com o chamado ciclo do ouro. Porém, para discussão neste trabalho, será considerada como referência a implantação da Mina de Casa de Pedra no município de Congonhas na década de 1940. Tal mina foi implantada com o objetivo de fornecer, de forma integral, a demanda de minério de ferro da Companhia Siderúrgica Nacional, implantada na mesma década no município de Volta Redonda, Rio de Janeiro (COMPANHIA SIDERÚRGICA NACIONAL, 2010). A implantação desses dois empreendimentos criou um fluxo que partia do município mineiro em direção ao Rio de Janeiro. Nesse período o município de Congonhas passou por um relativo processo de crescimento populacional e ampliação de atividades urbanas, concentrado principalmente na área urbana da sede municipal e em algumas localidades isoladas, situadas sobretudo ao longo da BR-3 (atual BR-040). Esse processo, apesar de não possuir amplitude regional, caracteriza o fluxo mencionado e estabelece o eixo da rodovia como elemento fundamental na indução da ocupação urbana na área. Outra característica importante desse processo é a construção, por parte do empreendedor, de vilas operárias para seus trabalhadores, o que se enquadra no modelo de relação empregador/empregado adotado à época em diversos empreendimentos industriais e minerários do país (GUNN; CORREIA, 2005).

Na década de 1970, com a crise do petróleo, o governo federal anunciou a elaboração do chamado Plano de Desenvolvimento Ferroviário, que envolvia, dentre outras ações, a implementação de locomotivas movidas à energia elétrica e a implantação de diversos trechos em diferentes partes do país. Dentre os trechos em estudo chamava a atenção a proposta de interligar, por vias férreas, as três maiores economias estaduais brasileiras (Minas Gerais, Rio de Janeiro e São Paulo). Esse trecho, apelidado de Ferrovia do Aço, seria a concretização da diretriz apresentada pela Rede Mineira de Viação em 1956, que consistia em uma linha especializada para o transporte de minério de ferro (MAGALHÃES, 1989). De acordo com o projeto da década de 1970, o ponto de partida do trecho seria Jeceaba, Minas Gerais, estratégico para o carregamento de minérios, e se direcionaria para Volta Redonda, no Rio de Janeiro, com ramais para o porto de Sepetiba (atual Porto de Itajaí), no Rio de Janeiro, e para o Estado de São Paulo. Foi prevista também a construção de uma linha articulando a Mina de Águas Claras, situada na divisa de Belo Horizonte e Nova Lima, com o trecho iniciado em Jeceaba (MAGALHÃES, 1989). Nesse projeto a importância da área de estudo como ponto estratégico para o escoamento de minérios fica evi-

Cadernos de Arquitetura e Utbanismo, v.17, n.21, 20 sem. 2010 
denciada, articulando-a tanto com as principais siderúrgicas do país quanto com os portos voltados à exportação de minérios. Os altos custos de implantação da Ferrovia do Aço e as diversas crises econômicas ocorridas ao longo da década de 1970 levaram o empreendimento a várias alterações na configuração do projeto e diversas paralisações na implantação da via, iniciada em 1976. Na década de 1980, quando havia, ao longo do trajeto, diversos túneis inacabados, vias parcialmente implantadas e viadutos não interligados, o governo federal decidiu concluir o trecho Jeceaba-Saudade, uma versão simplificada do projeto inicial (MAGALHÃES, 1989). Desse modo, no ano de 1989, após 14 anos, a Ferrovia do Aço foi inaugurada, o que ampliou a capacidade de tráfego da região e consolidou um segundo elemento fundamental para a conformação da rede urbana regional vivenciada duas décadas mais tarde.

No final da década de 1970 é iniciada a implantação da Aço Minas Gerais S.A. - Açominas, no município de Ouro Branco. Nesse processo, além da localização da usina, foi desenvolvido um significativo estudo para ampliação do núcleo urbano existente. O Plano de Desenvolvimento Urbano - PDU (Fundação João Pinheiro, 1978a), elaborado a partir de um núcleo urbano preexistente com cerca de quatro mil habitantes, previa a implantação de infraestrutura urbana capaz de abrigar, no curto prazo, um contingente populacional de cerca de sessenta mil pessoas. Havia também previsões quanto ao crescimento e adensamento do novo núcleo, de modo que em vinte anos a população estimada do município seria de cento e oitenta mil habitantes (Fundação João Pinheiro, 1976).

Nesse processo destaca-se a presença intensiva do Estado (no caso, o governo federal) na construção de um núcleo urbano de apoio à indústria. Essa situação trouxe a Ouro Branco uma peculiaridade em relação à sua estrutura fundiária, uma vez que, desde a consolidação desse processo, a Açominas (atual GerdauAçominas) tornou-se proprietária da maior parte dos terrenos urbanos e de expansão urbana do município.

Com um traçado fortemente influenciado pelos preceitos racionalistas, o tecido urbano proposto para a sede de Ouro Branco foi classificado em quatro zonas funcionais principais (área industrial, área urbana, área agrícola e área de preservação).

Havia a proposta inicial para que as novas áreas parceladas fossem ocupadas simultaneamente por funcionários da nova usina e pelo restante da população, numa proporção de $50 \%$ para cada categoria. No entanto, diante da necessidade de abrigar a mão de obra necessária à operação da primeira etapa da planta industrial, tal iniciativa foi temporariamente suspensa e, posteriormente, abandonada em definitivo (COSTA; COSTA, 1997). Assim, levando-se em conta que as áreas habitacionais possuíam lotes com dimensões e preços diferenciados, e grande parte da população trabalhava para o mesmo empregador, verificou-se, na prática, que a ocupação dos bairros se deu de acordo com a categoria funcional dos empregados do complexo siderúrgico (OURO BRANCO, 2006).

Em uma análise do PDU é possível notar a preocupação predominante com o apoio à usina em implantação e com os no- 
2. Dados extraídos dos Estudos Urbanísticos dos Planos Diretores Participativos de Entre Rios de Minas, Jeceaba e São Brás do Suaçuí, elaborados em 2008.

Cadernos de Arquitetura e Utbanismo, v.17, n.21, 20 sem. 2010 vos habitantes, sendo notadas deficiências quanto à população preexistente e precariedades quanto à articulação com o núcleo histórico. Apesar de citações no plano sobre o "envolvimento do núcleo antigo da cidade" (Fundação João Pinheiro, p. 1, 1978b), nota-se, a partir da implantação da indústria, um progressivo processo de descaracterização do centro histórico. Soma-se a isso o fato de a projeção populacional feita à época não ter se concretizado, uma vez que o município possui atualmente 32.553 habitantes (IBGE, 2010). Essa situação gerou na estrutura urbana da sede municipal uma série de áreas parceladas não ocupadas, situadas entre bairros consolidados. Essa questão merece ser aqui levantada, uma vez que se nota, na região em estudo, uma expectativa exagerada quanto ao fluxo de pessoas para a região. Essa expectativa tem sido observada recentemente e será objeto de discussão neste trabalho.

A partir da década de 1980, apesar da ausência de grandes investimentos na região, o município de Conselheiro Lafaiete se consolida enquanto polo voltado à prestação de serviços de apoio à mineração e à indústria. Juntamente com essas atividades são instalados, progressivamente, estabelecimentos comerciais e de serviço de apoio à população, tais como clínicas médicas, laboratórios e supermercados, dentre outros. Com o desenvolvimento e consolidação desse polo, os municípios citados começam a apresentar uma complementaridade de funções, sendo Congonhas um polo minerário, Ouro Branco um polo industrial e Conselheiro Lafaiete um polo comercial e de serviços. Apesar da ausência de um planejamento dotado de diretrizes voltadas à consolidação de Conselheiro Lafaiete como município dedicado à prestação de serviços, atribui-se a esse processo a disponibilidade de terrenos a custos relativamente baixos, se comparados com os valores praticados em Ouro Branco, e as condições de relevo melhores que as encontradas no município de Congonhas. A articulação das três sedes urbanas através da BR-040 pode também ser apontada como elemento estruturador desse processo.

Na década de 1990 a região passa a ser cortada, no eixo nortesul, pelo gasoduto-oleoduto que liga Belo Horizonte aos ramais do Rio de Janeiro e São Paulo. Essa intervenção, apesar de menos propagandeada que as demais, da à região o acesso a importantes fontes de energia.

Esse cenário permanece inalterado até o ano de 2007, quando o governo do Estado de Minas Gerais anuncia a construção do Distrito Industrial de Jeceaba no município de mesmo nome, para a implantação do complexo industrial da Vallourec Sumitomo do Brasil - VSB, voltado à produção de tubos de aço sem costura. Para se ter uma noção da magnitude do empreendimento, a área destinada à implantação do Distrito Industrial possui 11.872.120,00m² (Minas Gerais, 2007a), enquanto a soma dos perímetros urbanos das sedes municipais de Entre Rios de Minas, Jeceaba e São Brás do Suaçuí, localizadas na área de influência do DI, possui 24.661.914,84m², ou seja, a área de um único empreendimento corresponde a quase $50 \%$ da somatória das áreas dos principais núcleos urbanos do entorno. ${ }^{2}$

Nesse mesmo ano é também anunciada, pelo Governo do Estado, a implantação do Distrito Industrial de Congonhas, destinado à instalação de uma unidade siderúrgica da CSN voltada à 
produção de aço laminado. A área destinada à implantação do DI de Congonhas prevê dois polígonos, um para implantação e outro para ampliação, sendo a área dos distritos equivalente a $14.034 .410,27 \mathrm{~m}^{2}$ e $15.337 .075,79 \mathrm{~m}^{2}$ respectivamente. Levandose em conta que a mancha urbana da sede do município de Congonhas possui 9.944.875,91 $\mathrm{m}^{2}$ de área, é possível avaliar a dimensão do impacto causado na estrutura urbana local.

No mesmo ano a Gerdau-Açominas anuncia a expansão de seu complexo industrial e, em 2008, a Ferrous Resource do Brasil e a Nacional Minérios S.A. - Namisa, duas empresas mineradoras, anunciam a implantação de empreendimentos minerários no município de Congonhas.

\section{A configuração da rede urbana regional do Alto Paraopeba}

3. Neste trabalho serão também analisadas ações vinculadas às instâncias estaduais e federais cujos rebatimentos incidem diretamente sobre o planejamento e a gestão urbana municipal.

4. Para o aprofundamento dessa questão, ver Haesbaert (2007).

5. Santos (2008, p. 72) afirma que "os objetos são tudo o que existe na superfície da Terra, toda herança da história natural e todo resultado da ação humana que se objetivou". Nessa discussão considera-se mais apropriado destacar o meio físico (que contém objetos naturais associados, cada vez mais, a elementos e processos decorrentes da ação antrópica), dos objetos artificiais. Quanto às ações, Santos (2008) considera que estas são resultantes de necessidades que levam

o ser humano a agir e conduzem a funções que, por sua vez, irão constituir os objetos.

6. No caso brasileiro não pode ser desconsiderada a importância da instância administrativa enquanto

elemento formador de núcleos. Por todo território nacional são identificados municípios predominantemente suportados pelo aparato administrativo estatal.

7. No caso da usina da VSB em Jeceaba, o fornecimento principal de minério de ferro se dará ainda mais ao norte, através da Mina de Pau Branco, município de Brumadinho. Essa mina,

por sua vez, já fornece minério para outra siderúrgica, a unidade da Vallourec e Mannesman do Brasil Ltda, localizada na região do Barreiro, município de Belo Horizonte.

Cadernos de Arquitetura e Urbanismo, vil7, n.21, $2^{2}$ sem. 2010
A rede urbana regional é aqui entendida como o conjunto formado por diferentes núcleos cuja complementaridade funcional e seus respectivos fluxos e impactos ultrapassam os limites administrativos municipais.

No contexto brasileiro é fundamental empreender tal discussão, considerando-se o município como elemento-chave, uma vez que, conforme será discutido adiante, os instrumentos de planejamento e gestão urbana vigentes no Brasil colocam o município no primeiro plano da regência dessa matéria. Será abordado predominantemente o conceito de território político, vinculado à delimitação de espaços pertencentes a diferentes instâncias administrativas estatais. Devido à importância do território municipal na instrumentação legal da política urbana brasileira, as análises serão feitas a partir dessa delimitação. ${ }^{3}$ Levando-se em conta o foco desta discussão, não serão aqui abordadas as diferentes noções que compõem a chamada multiterritorialidade. ${ }^{4}$

O território municipal é ancorado sobre um meio físico que dá suporte à instalação de diferentes objetos e, consequentemente, à realização de diferentes ações. Tal meio físico é dotado de recursos cuja disponibilidade, acessibilidade e diversidade ampliam o potencial sistêmico de objetos e ações ${ }^{5}$ no território. A organização sistêmica desses objetos e ações configura núcleos, que podem ter especializações funcionais distintas, vinculadas principalmente à predominância de ocupações e usos. ${ }^{6}$

A necessidade de articulação entre núcleos funcionalmente distintos gera fluxos de naturezas e intensidades diversas que, em determinadas situações, atuam como indutores de novos núcleos.

A relação entre núcleos de especializações distintas e suas respectivas articulações gera a chamada complementaridade funcional, cuja análise permite avaliar em que níveis cada núcleo se insere na rede urbana.

No caso da rede urbana regional do Alto Paraopeba, sua ancoragem se dá a partir das diversas jazidas de minério de ferro localizadas principalmente no município de Congonhas. ${ }^{7}$ É inquestionável que o processo em tela não teria o mesmo vigor caso tal recurso não fosse tão presente. 
Figura 1 - Principais municípios da rede urbana do Alto Paraopeba e sua inserção no polígono do Quadrilátero Ferrífero.

Fonte: geógrafo Rafael Salomão, baseado em dados de Geominas, 1996.

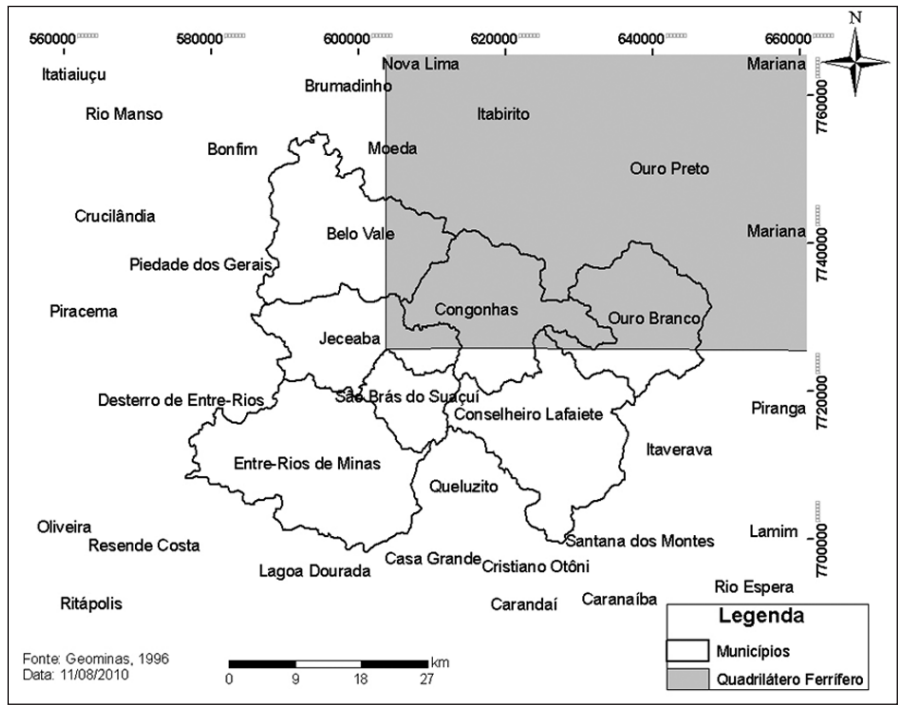

Uma questão relevante nessa análise se deve ao fato de tais jazidas serem o limite norte dessa rede urbana, estando, portanto, geograficamente na margem do território de análise. As minas de ferro da Vale do Rio Doce em Belo Vale e Congonhas e a Mina de Casa de Pedra em Congonhas estabelecem o primeiro estágio no processamento do minério e são, portanto, núcleos configuradores da rede. A articulação dessas minas em direção aos portos e unidades industriais estabelece um fluxo intenso de máquinas e equipamentos que, apesar de percebido desde o município de Nova Lima (cortando, no sentido norte-sul, o município de Itabirito e a porção oeste do município de Ouro Preto), intensifica-se a partir do município de Congonhas. Nesse trecho ressalta-se a articulação entre Congonhas, Ouro Branco e Conselheiro Lafaiete, formando um triângulo que, além do fluxo mencionado, é também pontuado por áreas urbanas isoladas, dentre as quais destacam-se Murtinho e Alto Maranhão, ambas localizadas no município de Congonhas.

As três unidades industriais representam, nesse contexto, o espaço de mediação do processo de transformação da commodity em produto de maior valor agregado. A previsão de se implantar uma rodovia de ligação entre os três empreendimentos (CSN, VSB e Gerdau-Açominas) e a BR-040, além interligar os três núcleos industriais, gera a tendência de ampliar a ocupação do solo com o uso habitacional de renda média-baixa na porção norte das áreas urbanas de Murtinho e Alto Maranhão.

A articulação entre esses diversos núcleos se dá de maneira diferenciada ao longo do território. Nota-se uma pressão quanto à expansão de áreas parceladas voltadas ao uso predominantemente residencial no município de São Brás do Suaçuí, um tensionamento decorrente da implantação da unidade da VSB em Jeceaba. A Mina de Casa de Pedra, por sua vez, estabelece uma pressão sobre a sede de Congonhas e os núcleos urbanos de Murtinho e Alto Maranhão, o que gera a tendência de ampliar as ocupações de uso predominantemente residencial nessa área.

No caso de Ouro Branco essa pressão é percebida de maneira diferenciada, uma vez que grandes porções do território são de 
propriedade da Gerdau-Açominas. Essa situação gera um controle sobre a terra urbana e inibe, principalmente em comparação com outros municípios da região, a pressão por novos parcelamentos.

As sedes de Entre Rios de Minas e Belo Vale, apesar de analisadas no âmbito da presente rede urbana, em função da maior distância em relação aos principais empreendimentos e, no caso de Belo Vale, da articulação rodoviária com menor capacidade e relevo acidentado, dão a esses dois núcleos uma tendência de menores impactos.

Desse modo, seria possível sintetizar os seguintes níveis de articulação regional:

- Articulação entre a Mina de Casa de Pedra, a sede urbana de Congonhas e a sede urbana de Conselheiro Lafaiete, dada através da BR-040;

- Articulação entre a Usina Gerdau-Açominas e a sede urbana de Conselheiro Lafaiete, dada através da MG-443 e da BR040;

- Articulação entre a sede urbana de Jeceaba - Usina VSB e a sede urbana de São Brás do Suaçuí, dada através da MG-155. Essa articulação, por sua vez, se liga à sede de Conselheiro Lafaiete através da MGT-383 e da BR-040.

Essas articulações mostram a importância de Conselheiro Lafaiete nessa rede urbana regional, e o transporte rodoviário como o principal meio de locomoção. Se, por um lado, tende a haver um fortalecimento dos municípios onde se localizam as plantas industriais (Congonhas, Ouro Branco e Jeceaba), Conselheiro Lafaiete, por outro lado, tende a absorver grande parte da reprodução ampliada da força de trabalho, tornando-se sede de serviços de escala regional.

\section{Quadro 1}

Municípios, populações e produtos internos brutos em 2008.

\begin{tabular}{l|l|l}
\hline Município & População (habitantes) & PIB (em reais) \\
\hline Belo Vale & 7.267 & $35.286 .000,00$ \\
\hline Congonhas & 44.950 & $468.430 .000,00$ \\
\hline Conselheiro Lafaiete & 111.460 & $596.590 .000,00$ \\
\hline Entre Rios de Minas & 13.650 & $55.030 .000,00$ \\
\hline Jeceaba & 5.570 & $17.480 .000,00$ \\
\hline Ouro Branco & 32.230 & $1.540 .000 .000,00$ \\
\hline São Brás do Suaçuí & 3.330 & $60.540 .000,00$ \\
\hline
\end{tabular}

Os números apresentados no quadro acima demonstram que o município de Conselheiro Lafaiete, apesar de não possuir nenhuma atividade extrativa ou industrial de grande porte, detinha o segundo maior PIB da região no ano de 2008, baseado em atividades comerciais e de serviço de apoio às populações locais e indústrias do entorno. Essa situação reforça a ideia de que Conselheiro Lafaiete, por já se configurar em um polo terciário, tenha seu papel ampliado a partir das novas inserções econômicas na região. Outro aspecto que reforça essa formulação é a sinergia que as atividades econômicas do terciário apresentam, o que as levaria para um local onde estas já existem. 
3. No período de levantamento de dados utilizados neste trabalho verificou-se, junto aos Executivos e Legislativos de Entre Rios de Minas, Jeceaba e São Brás do Suaçuí, que os dados constantes no relatório Perspectivas de Desenvolvimento do Alto Paraopeba (Codap, 2010) têm sido o material predominantemente utilizado, nesses municípios, na discussão da matéria. O Executivo de Congonhas disponibilizou o referido relatório na internet a partir do mês de maio de 2010

\section{Tendências e expectativas}

A discussão dos cenários tendenciais no âmbito deste trabalho necessita da inserção de uma variável vinculada à grande expectativa dos atores presentes na região. Será buscada uma comparação entre diferentes projeções e expectativas verificadas. Sabe-se que a região possui diversos empreendimentos em fase de estudo, e os números referentes aos valores de investimento, empregos diretos e indiretos gerados ainda não são muito precisos, o que gera a possibilidade de projeções superestimadas.

Dentre os dados cotejados para essa discussão destacam-se o Plano de Desenvolvimento Regional - Codap (Cedeplar, 2010) e o documento Perspectivas de Desenvolvimento do Alto Paraopeba (Codap, 2010).

Esse último possui uma formatação simplificada, cuja apresentação dos dados se dá de forma direta e sem o acompanhamento de análises fundamentais para o embasamento de tais resultados. Por outro lado, o Plano de Desenvolvimento Regional Codap (Cedeplar, 2010) tem o formato de relatório técnico, com a devida apresentação de metodologias e justificativas para os dados. Apesar da diferença metodológica entre os dois produtos, optou-se pela comparação entre eles, pois percebe-se que o produto elaborado pelo Cedeplar tem maior circulação entre o meio acadêmico e o governo estadual, enquanto o material apresentado pelo Consórcio Público para Desenvolvimento do Alto Paraopeba - Codap teve, por um período, maior receptividade junto aos Executivos e Legislativos municipais, sendo significativamente acessado pelos atores locais. ${ }^{3}$ Outra questão a ser levantada refere-se ao fato de o estudo elaborado pelo Cedeplar ter como proprietário o Codap. Dessa forma, os estudos não foram elaborados por atores obrigatoriamente divergentes, embora apresentem resultados distintos. Enquanto o plano elaborado pelo Cedeplar tem, como mencionado anteriormente, o caráter de um estudo técnico, o outro material tem um caráter de divulgação e, até mesmo, de exaltação.

Nos quadros a seguir são apresentadas as previsões de investimento dos principais projetos privados na região do Codap, provenientes dos estudos acima mencionados.

A comparação entre os dois quadros permite avaliar a discrepância entre os cenários previstos. Dentre esses dados o que mais se destaca é a previsão de empregos gerados. No caso do relatório Perspectivas de Desenvolvimento do Alto Paraopeba (Codap, 2010), os investimentos vinculados à CSN e à Namisa foram agrupados, o que de algum modo se justifica, uma vez que ambas pertencem ao mesmo grupo econômico. Independentemente disso, no referido relatório são previstos 12.000 empregos diretos e 45.000 empregos indiretos decorrentes da operação desses empreendimentos. De acordo com o Plano de Desenvolvimento Regional - Codap (Cedeplar, 2010), mesmo com o somatório de todos os empreendimentos vinculados à CSN e à Namisa, em um cenário classificado no plano como otimista, chega-se a uma previsão total de 5.600 empregos diretos e 11.800 empregos indiretos. Percebe-se a mesma diferença quando é feita a comparação entre os demais empreendimentos 


\section{Quadro 1}

Cenários e projetos na região do Codap apresentados no Plano de Desenvolvimento Regional (Cedeplar, 2010).

\begin{tabular}{|c|c|c|c|c|c|c|c|c|}
\hline Projeto & Localização & $\begin{array}{l}\text { Previsão } \\
\text { de início de } \\
\text { operação }\end{array}$ & $\begin{array}{l}\text { Valor } \\
\text { (US\$) } \\
\text { milhões }\end{array}$ & Produto & $\begin{array}{l}\text { Capacidade } \\
\text { atual }\end{array}$ & $\begin{array}{l}\text { Capacidade } \\
\text { futura }\end{array}$ & $\begin{array}{l}\text { Empregos } \\
\text { diretos } \\
\text { gerados }\end{array}$ & $\begin{array}{l}\text { Empregos } \\
\text { indiretos } \\
\text { gerados }\end{array}$ \\
\hline \multicolumn{9}{|c|}{ Cenário confirmado } \\
\hline $\begin{array}{l}\text { Vallourec Sumi- } \\
\text { tomo do Brasil }\end{array}$ & Jeceaba & 2011 & 1.600 & $\begin{array}{l}\text { Tubos de aço } \\
\text { sem costura }\end{array}$ & $\begin{array}{l}0,00 \text { tonela- } \\
\text { das de tubos }\end{array}$ & $\begin{array}{l}600 \text { mil } \\
\text { toneladas de } \\
\text { tubos }\end{array}$ & 1.500 & 1.500 \\
\hline $\begin{array}{l}\text { CSN Casa de } \\
\text { Pedra }\end{array}$ & Congonhas & 2011 & 500 & $\begin{array}{l}\text { Minério de } \\
\text { ferro }\end{array}$ & $\begin{array}{l}16 \text { milhões } \\
\text { de toneladas }\end{array}$ & $\begin{array}{l}40 \text { milhões de } \\
\text { toneladas }\end{array}$ & 2.500 & 7.500 \\
\hline Ferrous & Congonhas & 2013 & 2.740 & $\begin{array}{l}\text { Minério de } \\
\text { ferro }\end{array}$ & $\begin{array}{l}0,00 \text { tone- } \\
\text { ladas }\end{array}$ & $\begin{array}{l}25 \text { milhões de } \\
\text { toneladas }\end{array}$ & 1.200 & 3.600 \\
\hline Namisa & Congonhas & 2011 & 150 & $\begin{array}{l}\text { Minério de } \\
\text { ferro }\end{array}$ & $\begin{array}{l}6 \text { milhões de } \\
\text { toneladas }\end{array}$ & $\begin{array}{l}12 \text { milhões de } \\
\text { toneladas }\end{array}$ & 600 & 1.800 \\
\hline \multicolumn{9}{|l|}{ Cenário otimista } \\
\hline CSN Siderúrgica & Congonhas & 2015 & 3.100 & $\begin{array}{l}\text { aço laminado, } \\
\text { chapas } \\
\text { finas e } \\
\text { grossas }\end{array}$ & $\begin{array}{l}0,00 \text { tone- } \\
\text { ladas }\end{array}$ & $\begin{array}{l}4,5 \text { milhões } \\
\text { de toneladas }\end{array}$ & 2.500 & 2.500 \\
\hline $\begin{array}{l}\text { Gerdau-Aço- } \\
\text { minas }\end{array}$ & $\begin{array}{l}\text { Ouro } \\
\text { Branco }\end{array}$ & 2015 & 1.500 & $\begin{array}{l}\text { tarugos, } \\
\text { blocos, } \\
\text { chapas, } \\
\text { aço laminado }\end{array}$ & $\begin{array}{l}4,5 \text { milhões } \\
\text { de toneladas }\end{array}$ & $\begin{array}{l}5,5 \text { milhões } \\
\text { de toneladas }\end{array}$ & 826 & 500 \\
\hline
\end{tabular}

Fonte: Cedeplar, 2010.

\section{Quadro 2}

Investimentos previstos apresentados no documento Perspectivas de Desenvolvimento do Alto Paraopeba (Codap, 2010).

\begin{tabular}{|c|c|c|c|c|c|c|c|c|}
\hline Projeto & Localização & $\begin{array}{l}\text { Previsão } \\
\text { de início } \\
\text { de opera- } \\
\text { ção }\end{array}$ & $\begin{array}{l}\text { Valor } \\
(\mathrm{R} \$) \\
\text { milhões }\end{array}$ & Produto & $\begin{array}{l}\text { Empregos } \\
\text { gerados na } \\
\text { instalação }\end{array}$ & $\begin{array}{l}\text { Empregos } \\
\text { diretos } \\
\text { gerados }\end{array}$ & $\begin{array}{l}\text { Empregos } \\
\text { indiretos } \\
\text { gerados }\end{array}$ & $\begin{array}{l}\text { Outras informa- } \\
\text { ções }\end{array}$ \\
\hline $\begin{array}{l}\text { Vallourec Sumi- } \\
\text { tomo do Brasil }\end{array}$ & Jeceaba & 2010 & 3.300 & $\begin{array}{l}\text { Tubos de } \\
\text { aço sem } \\
\text { costura }\end{array}$ & 5.000 & 1.500 & 6.000 & $\begin{array}{l}\text { Plano de expan- } \\
\text { são já anunciado }\end{array}$ \\
\hline CSN / Namisa & Congonhas & - & 12.500 & $\begin{array}{l}\text { Minério de } \\
\text { ferro, pelo- } \\
\text { tas e aço }\end{array}$ & 28.000 & 12.000 & 45.000 & - \\
\hline Ferrous & Congonhas & - & 2.500 & $\begin{array}{l}\text { Minério de } \\
\text { ferro }\end{array}$ & 2.000 & 1.500 & 6.000 & $\begin{array}{l}\text { Previsão de } \\
\text { construção de } \\
\text { mineroduto }\end{array}$ \\
\hline $\begin{array}{l}\text { Gerdau-Aço- } \\
\text { minas }\end{array}$ & $\begin{array}{l}\text { Ouro } \\
\text { Branco }\end{array}$ & 2011 & 1.800 & $\begin{array}{l}\text { Laminador } \\
\text { de chapas } \\
\text { grossas }\end{array}$ & - & - & - & $\begin{array}{l}\text { Expansão do } \\
\text { laminador de } \\
\text { perfis }\end{array}$ \\
\hline $\begin{array}{l}\text { Outros investi- } \\
\text { mentos públicos } \\
\text { e privados }\end{array}$ & - & - & 500 & - & - & - & - & $\begin{array}{l}\text { Investimentos de } \\
\text { outras empresas } \\
\text { mineradoras; } \\
\text { empresas da } \\
\text { cadeia produtiva e } \\
\text { investimentos do } \\
\text { governo } \\
\text { estadual e federal }\end{array}$ \\
\hline
\end{tabular}

Fonte: Codap, 2010.

Cadernos de Arquitetura e Ubbanismo, v.17, n.21, 20 sem. 2010 
citados nos dois relatórios e, consequentemente, quando é realizado o somatório de todos os projetos. No relatório apresentado pelo Codap (2010) é previsto um total de 15.000 empregos diretos e 57.000 empregos indiretos decorrentes do somatório de todos os empreendimentos previstos ou em implantação na região. No relatório apresentado pelo Cedeplar (2010) chega-se a um total de 9.126 empregos diretos e 17.400 empregos indiretos, uma diferença muito significativa.

Observa-se essa mesma discrepância quando é feita a comparação entre as projeções populacionais.

No caso do Plano de Desenvolvimento Regional (Cedeplar, 2010), foram definidos três cenários para as projeções populacionais, a seguir apresentados:

- Cenário 1, denominado tendencial, sem os investimentos previstos para a região;

- Cenário 2, com a inclusão de parte dos investimentos previstos;

- Cenário 3, que prevê a implantação de todos os empreendimentos planejados.

Quadro 3

Projeções populacionais (2010-2025) apresentadas no Plano de Desenvolvimento Regional (Cedeplar, 2010).

\begin{tabular}{|c|c|c|c|c|c|}
\hline $\begin{array}{l}\text { Cenário } 1 \\
\text { (Tendencial) }\end{array}$ & 2010 & 2015 & 2020 & 2025 & $\begin{array}{l}\text { Taxa de crescimento } \\
2010-25(\%)\end{array}$ \\
\hline CODAP & 220.243 & 227.125 & 232.671 & 236.469 & 7,37 \\
\hline Belo Vale & 8.098 & 8.304 & 8.479 & 8.616 & 6,39 \\
\hline Congonhas & 45.568 & 47.551 & 49.241 & 50.561 & 10,96 \\
\hline Conselheiro Lafaiete & 112.915 & 117.551 & 121.503 & 124.589 & 10,34 \\
\hline Entre Rios de Minas & 13.743 & 14.032 & 14.278 & 14.471 & 5,30 \\
\hline Jeceaba & 5.488 & 5.203 & 4.960 & 4.770 & $-13,08$ \\
\hline Ouro Branco & 32.553 & 33.550 & 34.399 & 35.063 & 7,71 \\
\hline São Brás do Suaçuí & 3.345 & 3.374 & 3.398 & 3.417 & 2,15 \\
\hline Cenário 2 & 2010 & 2015 & 2020 & 2025 & $\begin{array}{l}\text { Taxa de crescimento } \\
2010-25(\%)\end{array}$ \\
\hline CODAP & 226.221 & 273.790 & 358.386 & 379.123 & 67,59 \\
\hline Belo Vale & 7.663 & 8.322 & 9.495 & 9.782 & 27,66 \\
\hline Congonhas & 47.877 & 61.125 & 84.686 & 90.462 & 88,95 \\
\hline Conselheiro Lafaiete & 108.754 & 129.607 & 166.691 & 175.781 & 61,63 \\
\hline Entre Rios de Minas & 13.736 & 15.304 & 18.093 & 18.777 & 36,70 \\
\hline Jeceaba & 9.242 & 11.663 & 15.970 & 17.025 & 84,22 \\
\hline Ouro Branco & 34.700 & 42.405 & 56.108 & 59.467 & 71,37 \\
\hline São Brás do Suaçuí & 4.250 & 5.363 & 7.343 & 7.828 & 84,22 \\
\hline Cenário 3 & 2010 & 2015 & 2020 & 2025 & $\begin{array}{l}\text { Taxa de crescimento } \\
2010-25(\%)\end{array}$ \\
\hline CODAP & 226.221 & 276.825 & 375.046 & 395.783 & 74,95 \\
\hline Belo Vale & 7.663 & 8.364 & 9.726 & 10.013 & 30,67 \\
\hline Congonhas & 47.877 & 61.971 & 89.326 & 95.102 & 98,64 \\
\hline Conselheiro Lafaiete & 108.754 & 130.937 & 173.994 & 183.084 & 68,35 \\
\hline Entre Rios de Minas & 13.736 & 15.404 & 18.643 & 19.326 & 40,70 \\
\hline Jeceaba & 9.242 & 11.818 & 16.818 & 17.873 & 93,39 \\
\hline Ouro Branco & 34.700 & 42.897 & 58.807 & 62.166 & 79,15 \\
\hline São Brás do Suaçuí & 4.250 & 5.434 & 7.733 & 8.218 & 93,39 \\
\hline
\end{tabular}

Fonte: Cedeplar, 2010e 


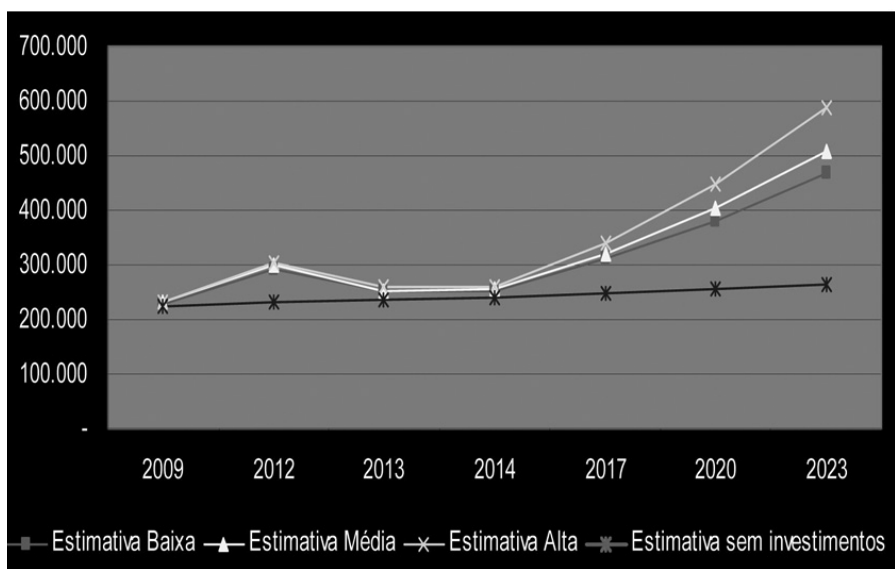

Figura 2 • Projeções populacionais para a região do Codap apresentadas no documento Perspectivas de Desenvolvimento do Alto Paraopeba (Codap, 2010).
Como pode ser verificado, há uma diferença muito significativa quanto às projeções populacionais previstas. No cenário 3, apresentado no Plano de Desenvolvimento Regional, é previsto, para o ano de 2025, um contingente populacional de 395.783 habitantes na região do Codap, enquanto no outro material é prevista, para o ano de 2023, uma população total de aproximadamente 590.000 habitantes.

Considera-se, para as situações apresentadas, que o relatório do Plano de Desenvolvimento Regional (Cedeplar, 2010) possui mais consistência e confiabilidade. O outro material se apresenta mais como uma espécie de apresentação parcial de dados que tem sido apropriada sem maiores critérios.

Ressalta-se também o risco de que dados superestimados em circulação possam ser usados indevidamente como instrumento de pressão para alterar as legislações urbanísticas, bem como para aprovar novos parcelamentos, ocupações e usos do solo sem os devidos estudos necessários aos seus respectivos processos de aprovação e implantação.

Expectativas exageradas já ocorreram na região, no período em que a Açominas foi implantada em Ouro Branco. Sabe-se que o momento histórico é outro, e não há, como houve em Ouro Branco, a presença intensiva do Estado na construção de uma nova cidade. Nesse contexto, faz-se necessário um aparato normativo capaz de regular, do ponto de vista urbanístico e ambiental, tais processos.

\section{Processos regionais, instrumentos urbanísticos municipais}

No presente estudo foram analisados três níveis principais de instâncias públicas com rebatimentos diretos nas questões vinculadas ao planejamento e à gestão urbana: a instância estadual, a instância regional e, por fim, as instâncias municipais. Além das instâncias públicas foram também analisadas as atuações de grupos econômicos privados.

Primeiramente cabe destacar o papel do governo estadual, uma vez que os distritos industriais de Jeceaba e Congonhas, destinados à implantação, respectivamente, das unidades industriais 
4. Na década de 1990, um período marcado por poucos investimentos em infraestrutura e indústrias, o Estado adotou um modelo em que grupos econômicos privados obtinham concessões para empreender todo o processo. Em alguns setores da infraestrutura, principalmente na implantação de centrais hidrelétricas, esse modelo sofreu forte resistência

da sociedade civil organizada, que alegava, dentre outras questões, que o capital privado estava tomando posse

de partes fundamentais da cadeia produtiva. Essa resistência, em diversas situações, atrasou cronogramas, elevou custos e, em situações específicas,

levou ao abandono de projetos. Mais recentemente, sobretudo a partir de 2005, verifica-se a presença do Estado nas etapas iniciais de projeto e implantação, com a concessão, a grupos privados, das etapas posteriores de empreendimentos dos setores de infraestrutura e indústrias. De posse de uma gama maior de instrumentos, como a declaração de utilidade pública, o Estado tem conseguido maior agilidade no licenciamento desses projetos.

Cadernos de Arquitetura e Utbanismo, v.17, n.21, $2^{0}$ sem. 2010 da VSB e da CSN, têm como empreendedor a Companhia de Desenvolvimento Econômico de Minas Gerais - Codemig, uma empresa vinculada ao Governo do Estado. Não é possível estabelecer exatamente onde é concluída a atuação do Estado e onde se inicia a ação dos grupos privados. Em tese, com base no que está divulgado e formalizado, o Estado é o responsável pelas etapas de projeto, licenciamento ambiental e implantação dos distritos industriais, enquanto os grupos privados empreendem o processo de implantação das plantas industriais. ${ }^{4}$ Cabe aqui uma rápida especulação sobre o nascedouro desses empreendimentos. Imagina-se uma planta, provavelmente na escala 1:25.000, onde são destacadas, em primeiro plano, as jazidas de minério, as minas implantadas e em implantação. Em uma segunda camada estariam as rodovias, ferrovias, o gasoduto e a hidrografia principal, na qual seria possível perceber a articulação potencial entre as minas e os portos. Em uma terceira camada estariam os limites do Brasil e de Minas Gerais. Ao fundo estariam os limites municipais na última camada considerada. Estariam verificadas nesse hipotético mapa as adequadas condições de implantação de usinas siderúrgicas na região.

Voltando à atuação da instância estadual, são acrescentados os projetos de expansão rodoviária, com o objetivo de articular os distritos industriais, minerações e núcleos urbanos. Estão previstas intervenções em cerca de $140 \mathrm{~km}$ de rodovias, dentre implantações e duplicações de trechos, nas quais destaca-se a construção do trecho que liga Jeceaba à BR-040, articulando potencialmente os três principais empreendimentos siderúrgicos da região (VSB, CSN e Gerdau-Açominas). Todos esses empreendimentos rodoviários são de responsabilidade do Departamento de Estradas de Rodagem de Minas Gerais - DER-MG, vinculado à instância estadual, que tem estabelecido parcerias junto aos municípios, a iniciativa privada e o governo federal para viabilizálos (Cedeplar, 2010).

Enquanto os distritos industriais são atratores de população, os eixos rodoviários são indutores de novos parcelamentos, ocupações e usos do solo. Desse modo, verifica-se que o governo estadual é um importante ator na configuração dessa rede urbana. Por outro lado, tal instância não dispõe de instrumentos de política urbana proporcionais à magnitude dos impactos por ela gerados.

No âmbito regional, as ações, por serem mais recentes, ainda não possuem resultados significativos em termos de planejamento e gestão urbana. Nesse sentido cabe mencionar a instituição do Consórcio Público para Desenvolvimento do Alto Paraopeba - Codap, constituído em 2006 com base na Lei Federal 11.107/2005 (Codap, 2010). Não será aqui discutida a potencialidade desse consórcio nos campos da saúde, educação, defesa civil, dentre outros, uma vez que o foco é a política e o estabelecimento de instrumentos urbanísticos de caráter regional. Nesse âmbito é citada a elaboração do Plano de Desenvolvimento Regional (Cedeplar, 2010), que inclui o dimensionamento de uma carteira de investimentos cujos projetos estruturantes são destacados em função dos impactos decorrentes da implantação de empreendimentos na região. Essa carteira de investimentos elenca também os empreendedores potenciais desses projetos, que podem ser 
desde os próprios municípios, os governos estadual e federal e a iniciativa privada, incluídas as possibilidades de parcerias. Essa carteira de investimentos, por ser geradora de diversas obras, tem forte potencial de implementação e, consequentemente, de geração de impactos sobre a estrutura urbana regional. Por outro lado, o estabelecimento de uma política urbana regional, integrada por todos os municípios, ainda é muito incipiente.

Para análise da política urbana municipal foi feito um estudo dos instrumentos urbanísticos vigentes nos municípios que constituem o Codap. Foram levantados, em cada município, os planos diretores municipais e as demais legislações urbanísticas, tais como leis de parcelamento, ocupação e uso do solo, leis de perímetros urbanos, códigos de obras e edificações e códigos de posturas.

Não é o caso de ser aqui apresentada uma análise individual dos instrumentos urbanísticos vigentes em cada município, mas sim discutir as perspectivas de integração regional e os obstáculos enfrentados para a consecução de tal objetivo.

Do ponto de vista da integração é ressaltada a tentativa da Secretaria Estadual de Desenvolvimento Regional e Política Urbana de Minas Gerais - Sedru de elaborar, de maneira integrada, os planos diretores de Entre Rios de Minas, Jeceaba e São Brás do Suaçuí nos anos de 2007 a 2009. Esses planos foram financiados pela VSB com base no disposto pelo artigo 41, inciso V da Lei Federal $n^{\circ} 10.257 / 2001$, que define a obrigatoriedade de elaboração de planos diretores para cidades "inseridas na área de influência de empreendimentos ou atividades com significativo impacto ambiental de âmbito regional ou nacional" (BRASIL, 2001, art. 41, inciso V). Elaborados com um caráter intermunicipal (a escala desses planos não pode ser considerada regional), os referidos planos foram submetidos, em um segundo momento, individualmente a cada Executivo Municipal, que na sequência os encaminhou aos Legislativos. Apesar das alterações sofridas ao longo do processo, nota-se que os termos adotados nos macrozoneamentos municipais e nos respectivos zoneamentos urbanos das sedes municipais são compatíveis entre si. Nota-se também o estabelecimento de macrozonas comuns a mais de um município, explicitando a tentativa de um planejamento em escala intermunicipal. Dentre estas destaca-se a macrozona do entorno imediato do Distrito Industrial (JECEABA, 2009a; SÃO BRÁS DO SUAÇUÍ, 2009a), presente nos planos diretores de Jeceaba e São Brás do Suaçuí, onde é estabelecida a restrição ao uso residencial no entorno imediato do Distrito Industrial de Jeceaba.

Ainda na esfera da aprovação dos planos diretores, chama a atenção o caso de Ouro Branco, em que uma diferença de interpretação entre o Executivo, que encaminhou o projeto de lei, e o Legislativo, com o papel de aprová-lo, levou à supressão, dentre outras matérias fundamentais, do macrozoneamento municipal. Os estudos referentes a essa lei, aprovada em 2007 (OURO BRANCO, 2007), foram retomados em 2009 pelo Executivo, que, através da Lei Municipal n¹794/2010 (OURO BRANCO, 2010), sancionou a Lei de Uso, Ocupação e Parcelamento do Solo e alterou a Lei do Plano Diretor, reconduzindo o macrozoneamento municipal e outros instrumentos urbanísticos ante- 
5. Além do plano diretor do Ouro Branco, revisado em 2010 (OURO BRANCO,

2010), Congonhas revisou seu plano diretor em 2009 (CONGONHAS, 2009). riormente suprimidos. Essa questão verificada em Ouro Branco mostra um grande obstáculo na consecução de um planejamento regional integrado, que é a falta de alinhamento entre diferentes instâncias municipais, o que, no caso de uma regionalização, necessitaria do envolvimento simultâneo de vários Executivos e Legislativos Municipais.

Nos demais planos diretores estudados não foram verificadas, além de breves citações textuais, maiores intenções em termos de planejamento regional. ${ }^{5}$

Mas o maior número de ações isoladas em termos de política urbana é verificado na regulamentação dos instrumentos urbanísticos.

Nesse cenário observa-se uma profusão de leis aprovadas recentemente, dentre as quais as mais relevantes serão aqui destacadas.

O município de Congonhas, através da lei Municipal n².942/2010 (CONGONHAS, 2010), regulamenta procedimentos para a regularização de construções clandestinas no município. Nessa lei é estabelecido que o desrespeito aos "recuos, taxa de ocupação, índice de aproveitamento e outros parâmetros da Lei de Uso e Ocupação do Solo" (CONGONHAS, 2010, art. 6', inciso I) não constitui obstáculo para a regularização dos imóveis.

Já a Lei n².684/2007, também do município de Congonhas, regulamenta construções e intervenções em áreas urbanas situadas às margens dos rios e cursos d'água. Em uma área cujos estudos regionais vinculados ao uso dos recursos hídricos (IGAM, 2005) apontam para o aumento do número de enchentes no período chuvoso, essa regulamentação é mais um gesto empreendido de em direções contrárias a diretrizes regionais.

Em Conselheiro Lafaiete chama a atenção a Lei Complementar $n^{\circ}$ 24/2010, que permite a ocupação de até $100 \%$ da área do lote, "mediante a construção de caixa de captação e drenagem que retarde o lançamento das águas pluviais" (CONSELHEIRO LAFAIETE, 2010, art. $2^{\circ}$ ).

Além dos casos acima mencionados, foram identificadas também ações isoladas com o objetivo de modificar a legislação vigente nos municípios de Jeceaba e São Brás do Suaçuí.

Em todos os municípios estudados nota-se também a falta de estruturas de gestão urbana capazes de promover uma adequada implementação desses instrumentos urbanísticos, bem como para aprovar e fiscalizar os novos parcelamentos, ocupações e usos do solo conforme os parâmetros estabelecidos.

\section{Considerações finais}

Como pode ser demonstrado nas discussões aqui apresentadas, o caminho para a implementação de instâncias de planejamento e gestão urbana regional na área de atuação do Codap apresentase longo e complexo.

Verifica-se a necessidade de uma instância integrada de planejamento capaz de consolidar políticas urbanas e superar incoerências. Soma-se a isso o desafio de uma gestão urbana em um 
6. A perspectiva de um Poder Executivo Regional associado a uma Câmara Legislativa Regional ainda é muito distante do contexto em tela. Desse modo, os aspectos positivos e negativos dessa possibilidade não são objeto de análise deste trabalho. contexto cujas demandas por novos parcelamentos, ocupações e mudanças no uso do solo se dão em condições de aprovação e fiscalização insuficientes para a demanda atualmente verificada.

Outra dificuldade encontrada está vinculada à enorme expectativa gerada pelo anúncio dos novos investimentos na região. A análise de diferentes dados demonstra que as mudanças, inquestionavelmente relevantes, serão menores que a esperada por diversos atores (locais ou não). Essa expectativa é a base de um processo especulativo que eleva significativamente o valor da terra, acarreta a implantação de um grande número de novos parcelamentos, novas ocupações (muitas delas em desconformidade com parâmetros urbanísticos estabelecidos) e usos do solo incompatíveis entre si. As administrações públicas municipais, com receio de perder popularidade, não têm se mostrado dispostas a adotar posturas divergentes daquelas baseadas nas expectativas exageradas de crescimento.

Tal cenário é agravado pelo fato de os municípios constituintes do Codap terem capacidades distintas de ampliar suas respectivas receitas. Municípios com menor potencial de crescimento econômico (dentre os quais destaca-se São Brás do Suaçuí) sofrem pressões capazes de ampliar significativamente seus tecidos urbanos, com tendência de predominância do uso residencial e insuficiência de atividades econômicas capazes de apoiar tal uso.

Considera-se que o cenário ideal teria como base o estabelecimento de uma política urbana integrada para os sete municípios que compõem o Codap.

Entende-se que o estabelecimento de diretrizes integradas seja possível, sobretudo em um contexto como o brasileiro, em que as diretrizes nem sempre são coerentes com suas respectivas regulamentações, que, por sua vez, são frequentemente descumpridas.

A regulamentação integrada de tais diretrizes mostra-se complexa, principalmente se for considerado que tal regulamentação necessitaria de tramitar em todos os Executivos e Legislativos Municipais, muito heterogêneos entre si. ${ }^{6}$

Em um cenário possível considera-se que a implementação, nos próximos anos, de uma instância técnica voltada à aprovação e à fiscalização de novos parcelamentos, ocupações e alterações de uso do solo, com o objetivo de apoiar os Executivos Municipais na gestão dessa matéria, já será um grande avanço na direção do planejamento regional pretendido.

\section{Referências}

BRASIL. República Federativa do Brasil. Constituição da República Federativa do Brasil de 1988. Brasília: Presidência da República, 1988.

BRASIL. República Federativa do Brasil. Lei n 10.257, de 10 de julho de 2001. Regulamenta os arts. 182 e 183 da Constituição Federal, estabelece diretrizes gerais da política urbana e dá outras providências. Brasília: Presidência da República, 2001. 
BRASIL. República Federativa do Brasil. Lei $n^{\circ}$ 6.766, de 19 de dezembro de 1979. Dispõe sobre o Parcelamento do Solo Urbano e dá outras providências. Brasília: Presidência da República, 1979.

BRASIL. República Federativa do Brasil. Lei $n^{\circ}$ 11.107, de 6 de abril de 2005. Dispõe sobre normas gerais de contratação de consórcios públicos e dá outras providências. Brasília: Presidência da República, 2005.

CEDEPLAR. Centro de Desenvolvimento do Planejamento Regional. Plano de Desenvolvimento Regional - Codap - Produto 5. Belo Horizonte: Cedeplar, 2010.

CODAP. Consórcio Público para Desenvolvimento do Alto Paraopeba. Perspectivas de Desenvolvimento do Alto Paraopeba. Conselheiro Lafaiete: Secretaria Executiva, 2010.

CODEMIG. Companhia de Desenvolvimento Econômico de Minas Gerais. Estudo de impacto ambiental do distrito industrial de Jeceaba. Belo Horizonte: Companhia de Desenvolvimento Econômico de Minas Gerais, 2007.

COMPANHIA SIDERÚRGICA NACIONAL. Portal CSN - Perfil. Disponível em: <http://www.csn.com.br/portal/page? pageid $=456,170479 \&$ dad $=$ portal\&_schema $=P O R T A L>$. Acesso em: 5 ago. 2010.

CONGONHAS. Prefeitura Municipal de Congonhas. Lei $\mathrm{n}^{\circ} 2.116$. Institui o Código de Obras do Município de Congonhas. Congonhas: Prefeitura Municipal, 1996.

CONGONHAS. Prefeitura Municipal de Congonhas. Lei nº 2.573. Define o perímetro urbano do distrito-sede e dos demais distritos do município de Congonhas, e dá outras providências. Congonhas: Prefeitura Municipal, 2005.

CONGONHAS. Prefeitura Municipal de Congonhas. Lei $n^{\circ} 2.621$. Institui o plano diretor de desenvolvimento municipal do município de Congonhas e dá outras providências. Congonhas: Prefeitura Municipal, 2006a.

CONGONHAS. Prefeitura Municipal de Congonhas. Lei $n^{\circ} 2.623$. Institui o código de posturas do município de Congonhas e dá outras providências. Congonhas: Prefeitura Municipal, 2006b.

CONGONHAS. Prefeitura Municipal de Congonhas. Lei $n^{\circ} 2.624$. Dispõe sobre normas de uso e ocupação do solo no município de Congonhas. Congonhas: Prefeitura Municipal, 2006c.

CONGONHAS. Prefeitura Municipal de Congonhas. Lei nº 2.684. Dispõe sobre emenda ao plano diretor, regulamentando as construções e intervenção em área urbana, situadas às margens dos rios e cursos d'água, e dá outras providências. Congonhas: Prefeitura Municipal, 2007.

CONGONHAS. Prefeitura Municipal de Congonhas. Lei n².916, de 30 de dezembro de 2009. Dispõe sobre a primeira etapa de revisão do plano diretor de desenvolvimento municipal de Congonhas, sobre alterações na Lei 2.621/2006 - plano diretor, Lei 2.624/2006 - uso e ocupação do solo e Lei n. ${ }^{\circ} 2.573 / 2005$, que define o perímetro urbano e dá outras providências. Congonhas: Prefeitura Municipal, 2009.

CONGONHAS. Prefeitura Municipal de Congonhas. Decreto $\mathrm{n}^{\circ}$ 5.044, de 11 de março de 2010. Regulamenta os artigos 138 a 
154 da Lei n 2.623 de 21 de junho de 2006 - código de posturas municipal. Congonhas: Prefeitura Municipal, 2010a.

CONGONHAS. Prefeitura Municipal de Congonhas. Lei n ${ }^{\circ} 2.942$, de 12 de março de 2010. Dispõe sobre a remissão de construções clandestinas ou irregulares no município de Congonhas. Congonhas: Prefeitura Municipal, 2010b.

CONSELHEIRO LAFAIETE. Prefeitura Municipal de Conselheiro Lafaiete. Lei $n^{\circ} 359 / 57$. Aprova o código de obras da Prefeitura Municipal de Conselheiro Lafaiete. Conselheiro Lafaiete: Prefeitura Municipal, 1957.

CONSELHEIRO LAFAIETE. Prefeitura Municipal de Conselheiro Lafaiete. Lei $n^{\circ} 3.609 / 95$. Altera disposições da Lei municipal $n^{\circ}$ 359 de 15 de julho de 1957 (código de obras) da Prefeitura Municipal de Conselheiro Lafaiete. Conselheiro Lafaiete: Prefeitura Municipal, 1995.

CONSELHEIRO LAFAIETE. Prefeitura Municipal de Conselheiro Lafaiete. Lei complementar $n^{\circ} 0004 / 99$. Institui o plano diretor do município de Conselheiro Lafaiete e dá outras providências. Conselheiro Lafaiete: Prefeitura Municipal, 1999.

CONSELHEIRO LAFAIETE. Prefeitura Municipal de Conselheiro Lafaiete. Lei $n^{\circ}$ 4.784, de 2 de dezembro de 2005. Autoriza o Executivo municipal a instituir no âmbito do município de ConseIheiro Lafaiete campanha de incentivo à construção civil através da isenção de impostos e taxas. Conselheiro Lafaiete: Prefeitura Municipal, 2005.

CONSELHEIRO LAFAIETE. Prefeitura Municipal de Conselheiro Lafaiete. Lei complementar $n^{\circ} 24$, de 21 de junho de 2010. Altera o $\S 1^{\circ}$ do art. 43 da Lei municipal $n^{\circ} 359$, de 15 de julho de 1957, código de obras do município de Conselheiro Lafaiete e o $\S 3^{\circ}$ do art. 16 da Lei municipal $n^{\circ} 3.003$, de 13 de novembro de 1991. Conselheiro Lafaiete: Prefeitura Municipal, 2010.

COSTA, Heloísa Soares de Moura; COSTA, Geraldo Magela. Ouro Branco/Açominas: um último capítulo da história da produção do espaço para a indústria? Belo Horizonte, Geonomos - Revista de Geociências, v. VI, p. 61-66, 1998.

ENTRE RIOS DE MINAS. Prefeitura Municipal de Entre Rios de Minas. Lei $n^{\circ} 1.546$, de 13 de julho de 2009. Institui o plano diretor participativo do município de Entre Rios de Minas e dá outras providências. Entre Rios de Minas: Prefeitura Municipal, 2009.

FUNDAÇÃO JOÃO PINHEIRO. Açominas. Termo de referência para ocupação do solo. Belo Horizonte: Fundação João Pinheiro, 1976.

FUNDAÇÃO JOÃO PINHEIRO. Plano de Desenvolvimento Urbano, Ouro Branco, Açominas, v. 1, texto. Belo Horizonte: Fundação João Pinheiro, Centro de Desenvolvimento Urbano, 1978a.

FUNDAÇÃO JOÃO PINHEIRO. Plano de Desenvolvimento Urbano, Ouro Branco, Açominas, v. 3, legislação urbana. Belo Horizonte: Fundação João Pinheiro, Centro de Desenvolvimento Urbano, 1978b.

GUNN, Philip; CORREIA, Telma de Barros. A industrialização brasileira e a dimensão geográfica dos estabelecimentos industriais. In: Revista Brasileira de Estudos Urbanos e Regionais, v. 7, n. 1. Associação Nacional de Pós-graduação e Pesquisa em 
Planejamento Urbano e Regional, 2005.

HAESBAERT, Rogério. O mito da desterritorialização: do "fim dos territórios" à multiterritorialidade. Rio de Janeiro: Bertrand Brasil, 2007.

IGAM. Instituto Mineiro de Gestão das Águas de Minas Gerais. Estudos das metas de qualidade da bacia hidrográfica do Rio Paraopeba - 2005: diagnóstico estratégico da bacia hidrográfica e cenários de desenvolvimento. Belo Horizonte: Igam, 2005.

INSTITUTO BRASILEIRO DE GEOGRAFIA E ESTATÍSTICA. IBGE. Cidades@. Disponível em: <http://www.ibge.gov.br/cidadesat/default.php>. Acesso em: 4 ago. 2010.

JECEABA. Prefeitura Municipal de Jeceaba. Lei Complementar $\mathrm{n}^{\circ} 8$ de 22 de abril de 2009. Institui o plano diretor participativo do município de Jeceaba e dá outras providências. Jeceaba: Prefeitura Municipal, 2009a.

JECEABA. Prefeitura Municipal de Jeceaba. Lei Complementar $\mathrm{n}^{\circ}$ 009/2009. Estabelece normas e condições para parcelamento, ocupação e uso do solo de Jeceaba - MG. Jeceaba: Prefeitura Municipal, 2009b.

JECEABA. Prefeitura Municipal de Jeceaba. Lei Ordinária $n^{\circ}$ 1090/2009. Dispõe sobre o perímetro urbano do município de Jeceaba e contém outras providências. Jeceaba: Prefeitura Municipal, 2009c.

MAGALHÃES, V. L. Ferrovia do aço. Rio de Janeiro: Revista Ferroviária, 1989.

MINAS GERAIS. Governo do Estado de Minas Gerais. Decreto sem número de 16 de abril de 2007. Estabelece os limites do Distrito Industrial de Jeceaba. Minas Gerais: Assembleia Legislativa, 2007a.

MINAS GERAIS. Governo do Estado de Minas Gerais. Decreto $\mathrm{n}^{\circ}$ 44.646, de 31 de outubro de 2007. Disciplina o exame e anuência prévia pelo Estado, por meio da Secretaria de Estado de Desenvolvimento Regional e Política Urbana - Sedru, para aprovação de projetos de loteamentos e desmembramentos de áreas para fins urbanos pelos municípios. Minas Gerais: Assembleia Legislativa, 2007b.

MINAS GERAIS. Governo do Estado de Minas Gerais. Decreto sem número de 12 de dezembro de 2007. Estabelece os limites do Distrito Industrial de Congonhas. Minas Gerais: Assembleia Legislativa, 2007c.

OURO BRANCO. Prefeitura Municipal de Ouro Branco. Lei 264/1979. Institui o código de posturas do município de Ouro Branco e contém outras providências. Ouro Branco: Prefeitura Municipal, 1979.

OURO BRANCO. Prefeitura Municipal de Ouro Branco. Lei $\mathrm{n}^{\circ}$ 1320/2001. Institui o código de obras do município de Ouro Branco e dá outras providências e revoga a Lei n 1.241/99. Ouro Branco: Prefeitura Municipal, 2001.

OURO BRANCO. Prefeitura Municipal de Ouro Branco. Lei $\mathrm{n}^{\circ}$ 1.619, de 13 de dezembro de 2007. Institui o plano diretor participativo do município de Ouro Branco e dá outras providências. Ouro Branco: Prefeitura Municipal, 2007. 
OURO BRANCO. Prefeitura Municipal de Ouro Branco. Lei 1.794/2010. Institui a Lei de Uso, Ocupação e Parcelamento do Solo do município de Ouro Branco, altera a Lei n 1.619, de 2007, que institui o plano diretor participativo e dá outras providências. Ouro Branco: Prefeitura Municipal, 2010.

SANTOS, Milton. A natureza do espaço: técnica e tempo, razão e emoção. São Paulo: Edusp, 2008.

SÃO BRÁS DO SUAÇUÍ. Prefeitura Municipal de São Brás do Suaçuí. Lei n ${ }^{\circ} 1.029$, de 31 de março de 2009. Institui o plano diretor participativo do município de São Brás do Suaçuí. São Brás do Suaçuí: Prefeitura Municipal, 2009a.

SÃO BRÁS DO SUAÇUÍ. Prefeitura Municipal de São Brás do Suaçuí. Lei $n^{\circ} 1.033$, de 6 de maio de 2009. Dispõe sobre o parcelamento, ocupação e uso do solo de São Brás do Suaçuí e contém outras providências. São Brás do Suaçuí: Prefeitura Municipal, 2009b.

SÃO BRÁS DO SUAÇUÍ. Prefeitura Municipal de São Brás do Suaçuí. Lei $n^{\circ} 1.038$, de 21 de maio de 2009. Dispõe sobre o código de obras e edificações de São Brás do Suaçuí e contém outras providências. São Brás do Suaçuí: Prefeitura Municipal, 2009c.

SÃO BRÁS DO SUAÇUÍ. Prefeitura Municipal de São Brás do Suaçuí. Lei ${ }^{\circ} 1.037$, de 21 de maio de 2009. Dispõe sobre o código de posturas do município de São Brás do Suaçuí e contém outras providências. São Brás do Suaçuí: Prefeitura Municipal, 2009d.

SÃO BRÁS DO SUAÇUí. Prefeitura Municipal de São Brás do Suaçuí. Lei $\mathrm{n}^{\circ}$ 1.039, de 29 de maio de 2009. Dispõe sobre o perímetro urbano do município de São Brás do Suaçuí e contém outras providências. São Brás do Suaçuí: Prefeitura Municipal, 2009 e.

\section{Endereço para correspondência}

Leandro de Aguiar e Souza

Rua Santa Cruz, n²44 - Alto Barroca

30430-430 - Belo Horizonte, Minas Gerais

leandrodeaguiar@yahoo.com.br 